\title{
Identifying and Ranking new product development critical factors based on marketing strategy case study Esfahan Steel Co.
}

\author{
Ehsan Dashtianeh¹, Reza Radfar², Abbas Toloui Eshlaghi² \\ ${ }^{1}$ Islamic Azad University, Department of Technology Management, Roudehen Branch, Roudehen, Iran \\ ${ }^{2}$ Islamic Azad University, Department of Technology Management, Science and Research Branch, Tehran, Iran
}

How to cite: Dashtianeh, E., Radfar, R. and Toloui Eshlaghi, A. (2021), "Identifying key success affecting on NPD based on marketing strategy case study Esfahan Steel Co.", Brazilian Journal of Operations \& Production Management, Vol. 18, No. 4, e2021944. https://doi.org/10.14488/BJOPM.2021.025

\begin{abstract}
Goal: Increasing orders and selling products are essential factors in designing all industries' strategy. To improving this factor, researchers have suggested many ways, such as new product development. By succeeding in designing and introducing a new product, each company would gain a better market share. One of the best examples of this $d$ innovation competition in companies is in the IT market where all companies compete for innovation and product development. Globally most of the roles are in common; however, some change according to the market, social, and political environment. For a successful new product in any industry, the marketing team should know their goal society's market environment and prioritize and choose the best marketing strategy according to their data analysis.
\end{abstract}

Design / Methodology / Approach: In this paper, initially, critical factors in successful new product development (NPD) at Esfahan Steel Co. are identified using a systematic literature review. Later, by using the information provided from the HR and marketing department of the Esfahan Steed Co., the designed questionnaire is asked to be filled by expertise, suppliers and customers. The collected data is analyzed by Technique for Order of Preference by Similarity to Ideal Solution (TOPSIS), and the main parameters affecting successful NPD is identified.

Results: In this study, fifteen factors are extracted from the literature and ranked by TOPSIS method. All of the fifteen factors are divided into five main categories: customer behavior, supplier, market, government strategy and social media. The results showed that the customer's needs and government role is the most crucial factor in alloy market.

Limitations of the investigation: In this study, the international sanctions imposed by the UN and the USA was intrusive variables that affected the study results, because this variable affected the study data and responder answer.

Practical implications: Market strategy is one of the essential factors of success in all companies. This study showed that the marketing strategy of Esfahan Steel Co. could be improved.

Originality / Value: This study highlighted the differences in Iran's steel market from other markets which are presented in the literature.

Keywords: New Product Development (NPD); Ranking; TOPSIS; Alloy Industries; Financial Sanctions.

\section{INTRODUCTION}

Esfahan Steel Co., founded in 1968, produces ten main steel products with variable sizes. The market size of this company was limited due to the inadequate variety of products. The

Financial support: None.

Conflict of interest: The authors have no conflict of interest to declare.

Corresponding author: dashtianeh@yahoo.com,r.radfar98@gmail.com

Received: 18 Mar 2020.

Approved: 22 Feb 2021.

Editor: Julio Vieira Neto. 
company was unable to answer all the local market demand despite the high quality of the product. The company has begun a new strategy to enlarge its product basket. To achieve this goal, a study should be carried out on NPD strategy to analyze the key factors on NPD of Esfahan Steel Co.

Today the research on new product development (NPD) and their effective factor has increased. All the strategists believe that NPD helps them improve their marketing by better understanding the product development. The literature on new product development has suggested factors such as 1-Customer 2- supplier 3- research and development center 4product line 5- market capacity 6- government policy 7- social network. (Svendsen et al., 2011).

Understanding customer behavior, opinions, needs, desires, budget, and social behavior helps firms choose the best strategy for designing their new product. In other words, the marketing team should understand their customer needs; also, they should know their supplier's ability to provide their requirement for a new product. In case a company would not pay attention to this fundamental rule (i.e., customer \& supplier demands) during their design, they would lose their market share to their rivals. Focusing on managing the relationship between these two factors should be the marketing team's main concert (Svendsen et al. 2011).

Another vital factor that extracted from literature involves customers and suppliers, which affects the new product success. Gathering questionaries about the requirements and skills of the customers and suppliers is the first step in NPD. This would help the strategist design the company's best strategy (Fantazy and Salem, 2016).

Next stage of NPD strategy involves their loyal customers. The company would introduce the new features of the new product to loyal customers (REF). Some studies focused on understanding the method of involving these customers and suppliers. Another part of the literature has investigated the methods of choosing loyal customers for this stage (REF).

Some studies on the same issue have revealed that factors such as two-sided guarantee, trust, compromise, and relationship management influence customer involvement (Lawson and Potter, 2012).

This study aims to rank the crucial components of the marketing strategy and study the impact of these factors on a new product development strategy. The product differentiation, competitor orientation, supplier skills, government influence, product line skills, social media and brand profiling are the most important factors of successful development. Other parameters depend on the behavior of the local market. These factors might change if the company has a global prospect; however, the marketing team should understand all aspect of the target market (Fantazy and Salem, 2016).

The definition of the NPD is explained here. Some sources defined NPD as a process in which a company converts data on market occasion and technical possibilities into information assets for commercial production. In this definition, the essential concept that is affected by NPD is the speed of development process related to product improvement.

On the other hand, another study reveals that if decreasing cycle time occurs, the profit will increase, and production time would be decreased. Therefore, by decreasing the cycle time, many financial benefits would be gained by the company. One of the main advantages is being the first company in the market which has enormous benefits such as pioneering in the market, customer attention, innovative reputation, and considerable investment return (Svendsen et al., 2011; Lim et al., 2006; Lindman, 2002). Several methods to reduce new product time has been introduced. Generally, before starting the process, the company's roadmap should be written, and then the engine of the new product should be ignited.

One of the critical factors mentioned in this study's begging is understanding customers needed in the product development process. Customer involvement in NPD model could be reduced or prevented in the costly futures changes, which substantially increases the new product development cycle time (Pitta 2005; Pasche et al. 2011; Kim et al., 2016). Engagement of the supplier to the NPD could help decrease the product development cycle time by shifting part of the new product development time to the suppliers and utilizing the suppliers' skills 
during the manufacturing process's debugging. Early engagement of the suppliers into the product development process can reduce the costs and decrease product development time. Nowadays, in the competitive international market, it is vital to incorporate the inputs of customers and to use the suppliers' resources to leverage the firm's capabilities in the product development process (Kim et al., 2018; Holtzman, 2014; Lawson and Potter, 2012).

Additionally, utilizing information technology can reduce the speed of decision-making and facilitate collaboration among customers, suppliers, and the company's personnel. Another related way of reducing new product development time is using virtual prototyping on the Internet and social network (Sai Hong and Ghobakhloo, 2013; Hsu, 2016).

Concurrent engineering lets overlapping new product development stages, thereby reducing overall new product development cycle time. This improves new product development performance by focusing on integrating internal product and process activities within a company. Though faster new product development time does not always lead to higher performance, it is considered a necessity for better performance. The Importance of fast new product development cycle time has been well documented in the literature, calling to investigate the role of new product introduction in the export development process (Nicholas et al., 2011; Woodcock et al., 2000; Hilmola et al., 2015).

Currently, Esfahan Steel Co. considers some of the abovementioned factors for effective NPD. However, for the local Iran market, other factors must be considered such as exclusive market without powerful rival in the domestic market, political decisions by the government in company's management, short-time management system (i.e., the short period of the managerial team in the company).

\section{BACKGROUND OF STUDY}

Recently many studies have been focused on this topic. For instance, Cazeri et al. (2019) investigated the product development process (PDP) by using 37 academic papers related to PDP. They divided their resources into five main categories: $27 \%$ was related to design performance, $5.5 \%$ to human resources, $62 \%$ to knowledge resources, $5.5 \%$ to financial performance.

Svendsen et al. (2011) investigated the marketing strategy and customer involvement in product development. Their results showed that two factors of marketing strategy, product differentiation, and competitor orientation, positively influence customer involvement. Furthermore, specific investments dedicated to the relationship were also positively related to customer involvement, and customer involvement increases customer profitability.

Lim et al. (2006) investigated the strategic impact of new product development on export involvement, and they concluded, faster new product development capability must be augmented for firms striving for a higher degree of export involvement. Additionally, the Importance of integrating the marketing, $R \& D$, and engineering functions to develop competitive advantage is highlighted in their research.

Lindman (2002) studied SMEs firms' new product development strategy; they found that SMEs tend to lack a long-run perspective.

In 2005, Pitta worked on market environmental system strategy of new product in china (Environmental Systems Controls), this research showed that information and action approach to new product developers is increased in global marketing.

Fantazy and Salem (2016) worked on the effects of strategy and R\&D on improving efficiency. Their findings indicated a direct positive association between NPD and performance. Additionally, their results indicated that R\&D (direct and indirect) positively influenced performance.

Sai Hong and Ghobakhloo (2013) worked on the effect of IT on Iranians' market. They show that IT leveraging competence in NPD and NPD effectiveness are valuable key capabilities that transform IT resources' value to a firm's performance for Iranian SBs. Investments in both technical and human IT resources have positive effects on the development of NPD capabilities. 
Those factors in the literature review, which is connected to the essential NPD factors of this research is illustrated in Table 1.

\section{RESEARCH METHODOLOGY}

In this study, A comparison between the critical NPD strategies of Esfahan Steel Co. and some other international companies has been carried out by reviewing 31 references. Later, the designed questionaries are sent to the experts, suppliers, and Esfahan Steel Co. customers. To understand each factor's impact on ranking all extracted factors (from the literature), TOPSIS is used.

After the systematic literature review (time limitation used to extract factors since 2000. Scholar google, Emerald publisher, Scopus and science direct used as a searching engine machine, New product development, strategy, R\&D used as Key word for searching), 15 critical factors were extracted and used in the questionnaire design. Those factors are illustrated in Table 1.

Table1- Important factor affecting NPD

\begin{tabular}{ccc}
\hline Item & Question & Reference \\
\hline 1 & Attention to the strategy of the company in NPD & Svendsen et al. (2011) \\
\hline 2 & Importance of customer needs in NPD & Svendsen et al. (2011) \\
\hline 3 & Importance of new features in NPD & Lindman (2002) \\
\hline 4 & Using NPD for finding new markets & Sai Hong and Ghobakhloo (2013) \\
\hline 5 & Difference of the product from a competitor in NPD & Goffin and New (2001) \\
\hline 6 & Ability of supplier in NPD & Lindman (2002) \\
\hline 7 & Effect of governmental law on NPD & Wang and Montaguti, (2002) \\
\hline 9 & Company technology can produce NPD & Kim et al. (2018) \\
\hline 10 & NPD helps increasing sell in the market & Lim et al. (2006) \\
\hline 11 & NPD affected on customer vision & Park, (2010) \\
\hline 12 & Effect of customers involvement in NPD & Nicholas et al. (2011) \\
\hline 13 & Effect of customer budget in NPD & Hilmola et al. (2015) \\
\hline 14 & Effect of market environment in NPD & Carísio de Paula et al. (2019) \\
\hline 15 & Effect of global market in NPD & Kim et al. (2016) \\
\hline
\end{tabular}

Questionnaires were sent to the experts (i.e., A person who has more than 20 years of experience in the steel industry). Questionnaires sent to 300 persons, among them 108 people took part in the research, which showed $90 \%$ confidence level and margin of error $6.4 \%$. Nonprobability sampling methods were used for sampling the data. The Likert scale was used in questionnaires, and each participant chose a value between 1-5 for any question (1 being the lowest). Likert-type or frequency scales were used to fix the choice response formats and were designed to measure the attitudes or opinions. These ordinal scales measured the levels of agreement/disagreement.

In this study, $90 \%$ of participants are male. $3 \%$ of the participants had a PhD level, $54 \%$ had an MSc, and $43 \%$ had a BSc degree. Age's comparison of participants shows that $18 \%$ of them are below 30, 37\% are between 30 and 40 years old, 39\% are between 40 and 50 years old, and $14 \%$ are above 50 years old. Participants' experiences show that $75 \%$ of them had less than ten years' experience, $23 \%$ had 10-20 years' experience, $8 \%$ had 20-30 years' experience, and $2 \%$ had more than 30 years' experience.

Table 2 shows the answer averages of 3 different group (experts, supplier, customer): 
Table 2- Answer average of experts, supplier, customer

\begin{tabular}{rrrrr}
\hline Item & Question & experts & supplier & Customer \\
\hline 1 & Importance of customer needs in NPD & 4.5 & 4.2 & 4.7 \\
\hline 2 & Effect of governmental law on NPD & 4.3 & 4.1 & 4.3 \\
\hline 3 & Ability of supplier in NPD & 4.4 & 4.4 & 4 \\
\hline 4 & Effect of Customer budget in NPD & 4.2 & 4 & 4.1 \\
\hline 5 & NPD affected on customer vision & 4.2 & 3.9 & 4 \\
\hline 6 & Attention to the strategy of the company in NPD & 4 & 3.9 & 3.9 \\
\hline 7 & Company technology has the ability to produce NPD & 3.9 & 3.8 & 3.8 \\
\hline 8 & Effect of market environment in NPD & 4 & 3.6 & 3.9 \\
\hline 9 & Importance of new features in NPD & 3.8 & 3.9 & 3.6 \\
\hline 10 & Effect of social media on NPD & 3.7 & 3.5 & 3.8 \\
\hline 11 & Using NPD to find new market & 3.6 & 3.4 & 3.6 \\
\hline 12 & NPD helps increasing sell in the market & 3.5 & 3 & 3.5 \\
\hline 13 & Difference of the product from a competitor in NPD & 3.3 & 3.2 & 3 \\
\hline 14 & Effect of customers involvement in NPD & 3 & 3.1 & 3.2 \\
\hline 15 & Effect of global market in NPD & 2.8 & 3 & 2.9 \\
\hline
\end{tabular}

The Technique for Order of Preference by Similarity to Ideal Solution (TOPSIS) is used to analyze the data. In 1987, Hawng and Yonn developed this multicritical decision technique, which was based on similarities and differences near the positive ideal solution (PIS) and negative ideal solution (NIS) (Hwang and Yoon, 1981). In this work multicriterial decision analyses methods (MCDA) were used. The gathered data were compared with the company's previous successful NPD data (which was taken from the R\&D department).

The TOPSIS process has six steps for ranking each item which is explained below: Saisse and Lima (2019)

Step 1: construct the decision matrix which is created from the data.

$D=\left[\begin{array}{ccc}A 11 & \cdots & A 115 \\ \vdots A 21 & \ldots & A 215 \vdots \\ A 31 & \ldots & A 315 \\ A 41 & \ldots & A 415 \\ \cdots & \cdots & \cdots \\ \cdots & \cdots & \cdots \\ A 1081 & \cdots & A 10815\end{array}\right]$

Where $A_{i j}$ is respond of expertise's $i$ to question of $j$ and then the rating of alternative Ai with respect to criterion $V_{i j}$ evaluated by an expert, and $A_{i j}^{k}=\left(A a_{i j}^{k}, b_{i j}^{k}, c_{i j}^{k}\right)$.

Step 2: calculate the normalized decision matrix for better understanding and comparison of the strategy factor. All the values are transformed to the same scale by equation number 2.

$$
r_{i j}=\frac{x_{i j}}{\sqrt{\sum_{i=l}^{108} x_{i j}^{2}}}
$$


Step 3. The weighted normalized decision matrix is shown as matrix $V$ calculated according to equation 3, in $V$ matrix each expertise (who has an experience more than 20 years in Steel industries) weighted all factor that extracted from literature.

$V=\left[v_{i j}\right]_{m^{*} n}, i=I, 2,3,4, \ldots . ., 15 ; j=1,2,3,4, \ldots \ldots, 108 V=\left[\begin{array}{ccc}0.9 & \ldots & 0.6 \\ \vdots 0.7 & \ldots & 0.7 \\ 0.9 & \ldots & 0.5 \\ 0.8 & \ldots & 0.6 \\ \ldots & \ldots & \ldots \\ \ldots & \ldots & \ldots \\ 0.9 & \cdots & 0.7\end{array}\right]$

$v_{i j}=r_{i j} * w_{j}$

Step 4: Determine the positive-ideal solution (PIS) and negative-ideal solution (NIS). According to the weighted normalized decision matrix, known as the elements $\sim \mathrm{m}_{\mathrm{ij}}$ are normalized positive TFNs, and their ranges belong to the closed interval $[0,1]$. Then, could define as the PIS A and NIS A_as Equation 5,6 :

$d_{i=1}^{-n}=\sum d\left(v_{i j}, v_{j}^{-}\right), i=1,2,3, \ldots ., m, j=1,2,3, \ldots \ldots, n$

$A^{-}=\left(V_{1}^{-}, V_{2}^{-}, V_{3}^{-}, \ldots, V_{n}^{-}\right)$

where $V_{j}^{+}=(1,1,1$,$) and V_{j}^{-}=(0,0,0) \mathrm{j}=1,2,3, \ldots ., \mathrm{n}$.

Step 5: Calculate the distance of each alternative from PIS and NIS. The distances $\left(d_{i}^{+}\right.$and $d_{i}^{-}$) of each alternative $\mathrm{A}$ from and $\mathrm{A}_{-}$can be currently calculated by the area compensation method.

$d_{i}^{+}=\sum_{j=1}^{n} d\left(v_{i j}, v_{j}^{+}\right), i=1,2,3, \ldots ., m, j=1,2,3, \ldots \ldots, n$

$d_{i=1}^{-n}=\sum d\left(v_{i j}, v_{j}^{-}\right), i=1,2,3, \ldots ., m, j=1,2,3, \ldots \ldots, n$

Step 6: Obtain the closeness coefficient and rank the order of alternatives.

\section{RESULT AND DISCUSSION}

A summary of the calculated results is presented in Table 3. These results show that the most critical factor is the Importance of customer needs in NPD, and conversely, the less critical factor is the Effect of Global market in NPD.

After ranking the factors, it is concluded that the key parameters are the customer, the government and their decision, respectively. The later factors make the difference between Esfahan Steel Co. and other international companies due to the UN and USA financial sanction. 
Table 3- calculated the TOPSIS data

\begin{tabular}{ccccc}
\hline Item & Question & $r_{j}$ & $d_{j}$ & $v_{j}$ \\
\hline 1 & Importance of customer needs in NPD & 0.021 & 0.0589 & 0.05301 \\
\hline 2 & Effect of governmental law on NPD & 0.024 & 0.0555 & 0.0444 \\
\hline 3 & Ability of supplier in NPD & 0.015 & 0.0532 & 0.03724 \\
\hline 4 & Effect of Customer budget in NPD & 0.016 & 0.0529 & 0.02645 \\
\hline 5 & NPD affected on customer vision & 0.022 & 0.0521 & 0.02084 \\
\hline 6 & Attention to the strategy of the company in NPD & 0.021 & 0.0512 & 0.01536 \\
\hline 7 & Company technology has the ability to produce NPD & 0.019 & 0.0498 & 0.00996 \\
\hline 8 & Effect of market environment in NPD & 0.018 & 0.0490 & 0.0049 \\
\hline 9 & Importance of new features in NPD & 0.023 & 0.0487 & 0.004383 \\
10 & Effect of social media on NPD & 0.020 & 0.0480 & 0.00384 \\
\hline 11 & Using NPD to find new market & 0.019 & 0.0456 & 0.003192 \\
\hline 12 & NPD helps increasing sell in the market & 0.019 & 0.0436 & 0.003052 \\
\hline 13 & Difference of the product from a competitor in NPD & 0.018 & 0.0421 & 0.002526 \\
\hline 14 & Effect of customers involvement in NPD & 0.012 & 0.0417 & 0.001668 \\
\hline 15 & Effect of global market in NPD & 0.011 & 0.0409 & 0.001227 \\
\hline
\end{tabular}

These factors are divided into five main categories: competitor, supplier ability, product line ability, and market and customer. In 2019 (that this study was carried out), Iranian industries were facing strict financial sanctions (especially in the steel and mine section). These sanctions affected the government behavior and decision; hence this significant factor affected participants' answers. As mention in the literature review, marketing and attention to the customers' needs were one of the most crucial factors. Thus, in Iranian industries and marketing atmosphere, in alloy industries (similar to those worldwide), attention to the customer needs should be the priority. The second parameter that the participants suggested was that the government and company's strategy, which has a negative effect (due to the sanctions). The third factor was the ability of the supplier to prepare intermediate materials for NPD. The fourth and fifth factors depend on the customers involving, and these two items indicated that for successful NPD, attention to the customers should be on priority.

Another vital factor that effected new product development is social media. This newly introduced factor has been represented after the Fourth Industrial Revolution. Nowadays, social media is involved in every moment of human life. Thus, all marketing strategies should consider this important factor. Due to the traditional vision of the people who are already working in Iran's steel sector, enough attention is not paid to social media and its potential. That is why the effect of social media on NPD is ranked 10 in this study. However, there is no need to say that this vision has to change, and more attention must be paid to social media for a successful NPD.

According to information received from TOPSIS methods (See table 3), the most critical factor sorted, and the priority of each factor is ranked. This table can guide the marketing team members in designing their NPD strategy in the Iranian steel market.

All in all, market, customer behavior, competitor, industry technology, and supplier ability are essential factors to engage shareholders to invest in NPD. For attracting investors, it is suggested that all factors investigated in this research are vital and must be considered in designing the development route. 


\section{CONCLUSION}

In this paper, after defining 15 critical factors for NPD, questionnaires were used to rank the factors. TOPSIS method was used for ranking those factors. Three main groups answered the questionaries (i.e., experts, supplier and customer of Esfahan Steel Co.). Results highlighted that the literature review was precise, and the critical factor was governmental laws and regulation. Moreover, this study showed that social media could be a helpful tool for marketing in modern times.

In Iran's Economy most unpredictable item that has affected the NPD is the strict sanctions. This uncertainty has affected other variables such as customer, governmental laws and regulation, and market state. Unstable conditions in Iran's economy has triggered low investment in industries and gradual industrial development.

Two crucial factors mentioned in the literature were the difference of product from a competitor in NPD and the effect of the global market in NPD. However, in Iranian alloys' market because of the sanctions, these factors lose their Importance. Hence before the sanctions, all the development strategies had a global vision.

The potential of the product line was another variable which must be considered in the NPD. This variable affected human resources, technology, and suppliers.

Iran's economy, rival companies' condition, and the product line's potential were included as the control variables of all the factors. Results showed that for improving the new product's performance, development attention must focus on the market situation, customer needs and condition of the rival. On the contrary, governmental laws and international sanctions harmed all marketing. This study was done during the sanctions and hence participants' opinions affected by this situation and environment.

This research suggests better international relations and change in the government's role from decision-maker to supporter for financial improvements. Additionally, one of the best tools that increase NPD efficiency is social media.

For further research, it is suggested that social media's effect on all five main new product development categories would be analyzed.

This study occurred during the COVID-19 pandemic, making it hard to access the participants and gather the data. Furthermore, due to confidentiality, full access to Esfahan Steel Co.'s research archive was restricted.

\section{REFERENCES}

Carísio de Paula, I., Augusto Hoppe, D., Maria Marx, Â. et al. (2019), "Procedure for identifying factors and interfaces that are critical in a sustainable product", Brazilian Journal of Operations \& Production Management, Vol. 16, pp. 126-40.

Cazeri, G., Ordoñez, R., Anholon, R. et al. (2019), "Performance measurement in product development process (PDP): literature review and gaps for further research", Brazilian Journal of Operations \& Production Management, Vol. 16, No. 4, pp. https://doi.org/https://doi.org/10.14488/BJOPM.2019.v16.n4.a1

Fantazy, K.A. and Salem, M. (2016), "The value of strategy and flexibility in new product development: the impact on performance", Journal of Enterprise Information Management, Vol. 29, No. 4, pp. 525-48.

Goffin, K. and New, C. (2001), "Customer support and new product development - An exploratory study", International Journal of Operations \& Production Management, Vol. 21, No. 3, pp. 275-301.

Hilmola, O.-P., Lorentz, H., Hilletofth, P. et al. (2015), "Manufacturing strategy in SMEs and its performance implications", Industrial Management \& Data Systems, Vol. 115, No. 6, pp. 1004-21.

Holtzman, Y. (2014), "A strategy of innovation through the development of a portfolio of innovation capabilities", Journal of Management Development, Vol. 33, No. 1, pp. 24-31.

Hwang, C.L. and Yoon, K. (1981), "Methods for multiple attribute decision making", in Hwang, C.L. and Yoon, K. Multiple Attribute Decision Making. Lecture Notes in Economics and Mathematical Systems, Springer, Berlin, Heidelberg. Vol. 186. https://doi.org/10.1007/978-3-642-48318-9_3.

Hsu, Y. (2016), "A value cocreation strategy model for improving product development performance", Journal of Business and Industrial Marketing, Vol. 31, No. 5, pp. 695-715. 
Kim, M., Ji-eung, K., Yeong-wha, S. et al. (2018), "Impacts of innovation type SME's R\&D capability on patent and new product development", Asia Pacific Journal of Innovation and Entrepreneurship, Vol. 12, No. 1, pp. 45-61.

Kim, Y.-H., Park, S.-W. and Sawng, Y.-W. (2016), "Improving new product development (NPD) process by analyzing failure cases", Asia Pacific Journal of Innovation and Entrepreneurship, Vol. 10, No. 1, pp. 13450.

Lawson, B. and Potter, A. (2012), "Determinants of knowledge transfer in inter-firm new product development projects", International Journal of Operations \& Production Management, Vol. 32, No. 10, pp. 1228-47.

Lim, J.-S., Sharkey, T.W. and Heinrichs, J.H. (2006), "Strategic impact of new product development on export involvement", European Journal of Marketing, Vol. 40, No. 1-2, pp. 44-60. http://dx.doi.org/10.1108/03090560610637301.

Lindman, M.T. (2002), "Open or closed strategy in developing new products? A case study of industrial NPD in SMEs", European Journal of Innovation Management, Vol. 5, No. 4, pp. 224-36.

Nicholas, J., Ledwith, A. and Perks, H. (2011), "New product development best practice in SME and large organizations: theory vs practice", European Journal of Innovation Management, Vol. 14, No. 2, pp. 227 51.

Park, Y.H. (2010), "A study of risk management and performance measures on new product development", Asian Journal on Quality, Vol. 11, No. 1, pp. 39-48.

Pasche, M., Persson, M. and Löfsten, H. (2011), "Effects of platforms on new product development projects", International Journal of Operations \& Production Management, Vol. 31, No. 11, pp. 1144-63.

Pitta, D. (2005), "From market entry to new product development in China: environmental systems controls", Journal of Product and Brand Management, Vol. 14, No. 2, pp. 119-22.

Saisse, R.L.G. and Lima, G.B.A. (2019), "Similarity modeling with ideal solution for comparative analysis of projects in the context of the additional brics proposal", Brazilian Journal of Operations \& Production Management, Vol. 16, pp. 659-71.

Sai Hong, T. and Ghobakhloo, M. (2013), "IT investments and product development effectiveness: Iranian SBs", Industrial Management \& Data Systems, Vol. 113, No. 2, pp. 265-93.

Svendsen, M.F., Haugland, S.A., Grønhaug, K. et al. (2011), "Marketing strategy and customer involvement in product development", European Journal of Marketing, Vol. 45, No. 4, pp. 513-30. http://dx.doi.org/10.1108/03090561111111316.

Wang, Q. and Montaguti, E. (2002), "The R\&D-marketing interface and new product entry strategy", Marketing Intelligence \& Planning, Vol. 20, No. 2, pp. 82-5.

Woodcock, D.J., Mosey, S.P. and Wood, T.B.W. (2000), "New product development in British SMEs", European Journal of Innovation Management, Vol. 3, No. 4, pp. 212-22.

Author contributions: Ehsan Dashtianeh: literature review, interview coordination; Reza Radfar: statistical analysis; Abas Tolouie Eshlaghi: manuscript correction. All authors read and approved the final manuscript. 